\title{
TREATMENT OF DISTILLERY SPENT WASH BY COMBINED UF AND RO PROCESSES
}

\author{
Z.V.P. MURTHY ${ }^{1, *}$ \\ L.B. CHAUDHARI ${ }^{1,2}$
}

\author{
${ }^{1}$ Department of Chemical Engineering, \\ S.V. National Institute of Technology \\ Ichchhanath, Surat - 395 007, Gujarat, India \\ ${ }^{2}$ Department of Chemical Engineering, N.G.Patel Polytechnic \\ At:Isroli-Afwa, Po.Afwa, Tal.Bardoli, \\ Dist.Surat - 394 620, Gujarat, India
}

Received: 01/08/08

Accepted: 05/10/08 *to whom all correspondence should be addressed: e-mail: zvpm2000@yahoo.com

\begin{abstract}
The present study deals with the treatment of distillery spent wash by an ultrafiltration (UF) membrane followed by reverse osmosis (RO) membrane on a pilot scale membrane setup. The performance of the system was evaluated by varying applied pressure on the thin-film composite polyamide (TFC-PA) UF and RO membranes. In the first stage, UF experiments are carried out for concentration of effluents by removing the suspended solids (SS). RO has effectively separated the total dissolved solids (TDS), chemical oxygen demand (COD), biochemical oxygen demand (BOD), sulphate and potassium with the rejection efficiency of $97.9 \%, 96.8 \%, 97.9 \%, 99.7 \%$ and $94.65 \%$, respectively. UF was effective for the separation of SS with the rejection efficiency of $95.5 \%$. The pollutant level in permeate are below the maximum contaminant level as per the guidelines of the World Health Organization and the Central Pollution Control Board (CPCB) of India specifications for effluent discharge (less than $1000 \mathrm{ppm}$ of TDS and $500 \mathrm{ppm}$ of COD).
\end{abstract}

KEYWORDS: Distillery effluent; Spentwash; Ultrafiltration; Reverse osmosis.

\section{INTRODUCTION}

The Indian distillery units use sugarcane molasses as a preferred raw material because of its easy and large scale availability. There are about 579 sugar mills and 295 distilleries in India. Alcohol is produced from molasses by two types of fermentation processes, Praj type and Alfa Laval distillation. In Praj type, for one liter of alcohol produced, about 12- 15 liters of spentwash is generated, whereas, in the Alfa Laval continuous fermentation and distillation process only 7-8 liters of wastewater per liter of alcohol is produced as it uses evaporators for concentrating the effluent. Currently, about 40.72 million $\mathrm{m}^{3}$ of spentwash is generated annually from distilleries alone in India (Saha et al., 2005; Pant and Adholeya, 2007; Belkacemi et al., 2000; Dahiya et al., 2001; Sangave and Pandit, 2006). Ground water is the main water source for these operations. Significant volume of water is consumed for molasses preparation, yeast propagation etc. in the range of $14-22 \mathrm{II}^{-1}$ of alcohol production. The production and characteristics of spentwash are highly variable and dependent on feed stocks and various aspects of the ethanol production process. The spentwash is acidic $(\mathrm{pH}$ 3.94 - 4.30) dark brown liquid with high BOD (45000-100000 $\mathrm{mg} \mathrm{l}^{-1}$ ) and COD (90000$210000 \mathrm{mg} \mathrm{l}^{-1}$ ), and emits obnoxious odour. Although it does not contain toxic substances, its discharge without any treatment brings about immediate discolouration and depletion of dissolved oxygen in the receiving water streams, posing serious threat to the aquatic flora and fauna (Mane et al., 2006). Membrane based separation processes like ultrafiltration (UF), nanofiltration (NF), reverse osmosis (RO) and membrane bioreactor (MBR) have been applied for treating distillery effluent (Nataraj et al., 2006; Couallier et al., 2006; Zhang et al., 
2006). Distilleries are one of the 17 most polluting industries listed by the Central Pollution Control Board (CPCB) of India (CPCB, 2003). Indian distilleries employ various forms of primary, secondary and tertiary treatments of wastewater. The typical treatment sequence is screening and equalization, followed by biomethanation. Ferti-irrigation and biocomposting with sugarcane pressmud are the most widely used options for effluent disposal (Ramana et al., 2002). However, these methods are highly energy intensive and hence quite expensive. These disadvantages emphasized the need for further research using novel separation methods.

The main objective of this study is to purify the wastewater by removing the colour and the contaminants by using UF and RO membranes. Experiments are conducted at different operating pressures. The results are presented for the waste effluent samples collected from the local distillery industries.

\section{MATERIALS AND METHODS}

The experiments are performed on a Perma ${ }^{\circledR}$-pilot scale membrane system (Permionics, Vadodara, India) consisting of a spiral-wound TFC-PA UF and RO membrane modules. These membranes have three layers. The first layer (also known as skin layer) is of $5-20 \mu \mathrm{m}$ thick TFC-PA layer that does the actual separation. The second layer is made of polysulfone of about $50 \mu \mathrm{m}$ thickness, which provides support to the first layer (skin layer) as a substrate for cross-linking of composite layer. The third layer, used for resistance and strength, is made of polyester with a thickness of about $200 \mu \mathrm{m}$. The Perma-TFC membranes are capable of withstanding $\mathrm{pH}$ in the range 2-12, pressure up to $30 \mathrm{~atm}$ and temperatures up to $50^{\circ} \mathrm{C}$ with an effective area of $1.0 \mathrm{~m}^{2}$, module length 21 inches and diameter 2.5 inches. The experimental set-up is shown in Figure 1. A damper is provided to regulate the flow fluctuation due to the reciprocating action of the pump. A feed tank of 25 I capacity, made of stainless steel-316 is provided for storage and supply of effluent to the system as well as collection of the recycled concentrate. A cooling coil is installed inside the feed tank for circulating cold water to maintain constant feed temperature within the range of $28-30^{\circ} \mathrm{C}$. The effluent sample is collected from the local distillery industry situated in south Gujarat, India. Twenty five liters of the spentwash feed is poured in the feed tank after thoroughly cleaning the membrane systems and wetting with deionized water. The high pressure reciprocating pump is employed to transport the feed to the spiral wound membrane module. With a control valve, the retentate flow rate is maintained constant $\left(15 \mathrm{I} \mathrm{min}^{-1}\right)$ throughout the experiments, to ensure the steady hydrodynamic conditions inside the membrane module. Fouling of the membrane surface is the bane of membrane operations. Fouling layers are removed by using appropriate cleaning. The $\mathrm{CaCO}_{3}$ scaling is controlled by treating the membrane at the end of the day's study with dilute $\mathrm{HCl}$ solution, which converts the carbonate to $\mathrm{CO}_{2}$ and also removes other metal precipitates and mineral scales. To prevent biological fouling, the membrane is washed thoroughly with deionized water and stored in a $0.5 \%$ solution of sodium bisulfate $\left(\mathrm{NaHSO}_{3}\right)$ at the experiment runs. Washing with a $1-1.5 \%$ aqueous solution of tetrasodium EDTA, a chelating agent useful in removing organics and silt, is done on alternate days. The important parameters like colour, $\mathrm{pH}$, suspended solids (SS), total dissolved solids (TDS), COD, BOD, potassium, sulfate and chlorides are measured for the feed and permeate samples, according to standard methods (Clesceri et al., 1998).

In RO/NF/UF membrane processes, separation performance of the membrane is judged by the percent observed solute rejection $\left(R_{0}\right)$ of SS, COD, TDS and other feed components which is calculate as (Murthy and Gupta, 1997):

$\% R_{O}=\left(1-\frac{C_{p}}{C_{f}}\right) \times 100$

where $C_{f}$ and $C_{p}$ are the individual component concentrations in the incoming feed to the membrane system and in the permeate from the system, respectively. 


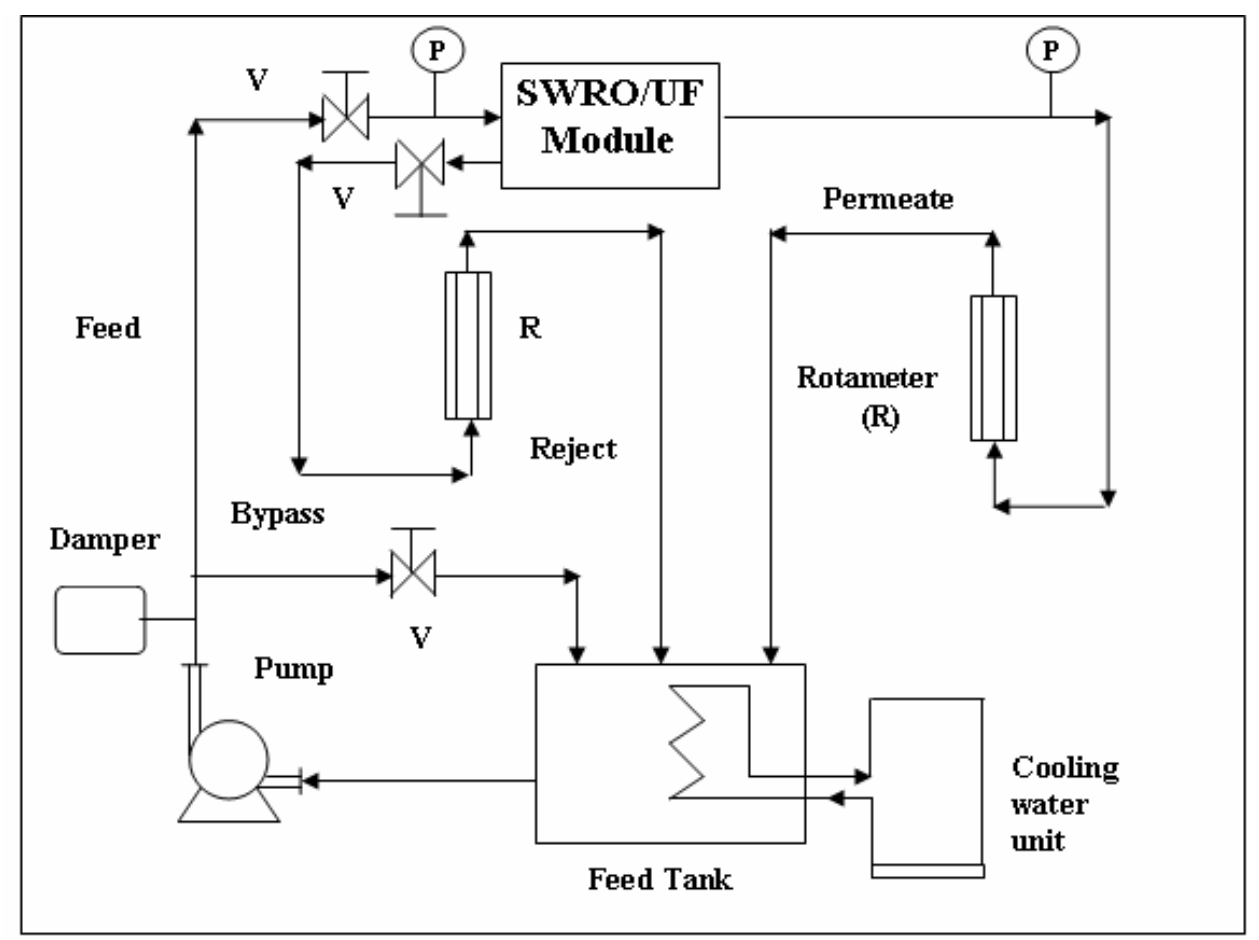

Figure 1. Perma ${ }^{\circledR}$-pilot scale membrane system

\section{RESULTS AND DISCUSSION}

\subsection{UF experiments}

The characteristics of the distillery spent wash used for this study are given in Table 1 . In the first stage, UF experiments were carried out for concentration of effluents by removing the suspended solids.

Table 1. Characteristics of distillery spent wash

\begin{tabular}{lcc}
\hline Parameter & Unit & Value \\
\hline $\mathrm{pH}$ & - & 4.01 \\
$\mathrm{SS}$ & $\mathrm{mg} \mathrm{I}^{-1}$ & 25040 \\
TDS & $\mathrm{mg} \mathrm{I}^{-1}$ & 38140 \\
COD & $\mathrm{mg} \mathrm{l}^{-1}$ & 125000 \\
Colour & Pt. Co. Scale & 800 \\
Chloride & $\mathrm{mg} \mathrm{I}^{-1}$ & 59981 \\
Sulphate & $\mathrm{mg} \mathrm{I}^{-1}$ & 25920 \\
BOD & $\mathrm{mg} \mathrm{l}^{-1}$ & 41946 \\
Potassium & $\mathrm{mg} \mathrm{l}^{-1}$ & 4360 \\
\hline
\end{tabular}

UF has effectively separated the SS from 25040 to $1127 \mathrm{mg} \mathrm{l}^{-1}$; COD from 125000 to 4600 ppm at pressure $10 \mathrm{~atm}$, with $R_{0}$ of $95.5 \%$ and $63 \%$, respectively. Effect of pressure on the removal efficiency of SS and COD by UF is shown through Figures $2-3$.

It can be seen from Figures 2 and 3 that the percentage rejection of SS increased from 57.3 to $95.5 \%$ with increasing the pressure from 2 to $10 \mathrm{~atm}$, while COD rejection increased from 26.4 to $63 \%$. With the pressure range of 2-10 atm, experimental results show that the removal of BOD is from 41946 to $24127 \mathrm{ppm}$, colour from 800 to $398 \mathrm{Pt}$-Co unit and potassium from 4360 to $2674 \mathrm{ppm}$ with $R_{0}$ being $42 \%, 50 \%$ and $39 \%$, respectively. There was a marginal reduction by UF in TDS from 38140 to $33561 \mathrm{ppm}$ with $R_{o}$ of $12 \%$. Effect of feed pressure on the removal efficiency of different ions through UF module is shown in Table 2. 


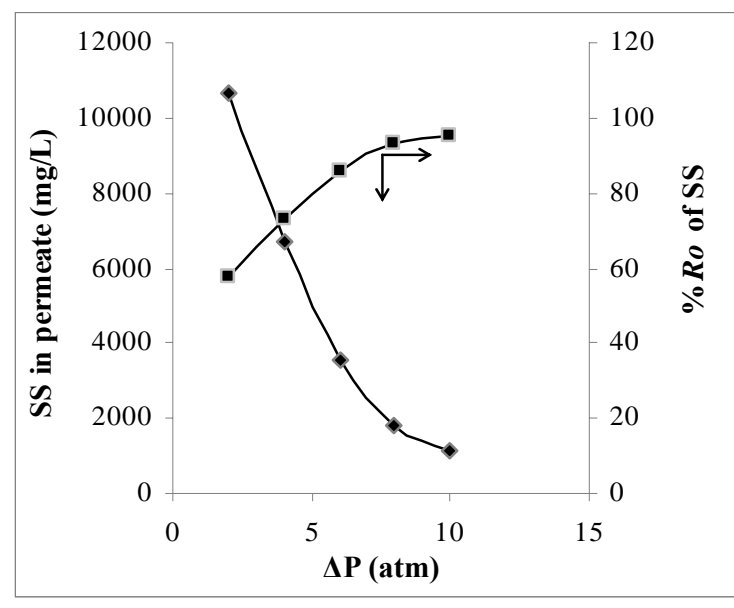

Figure 2. Removal of SS as a function of pressure with UF process

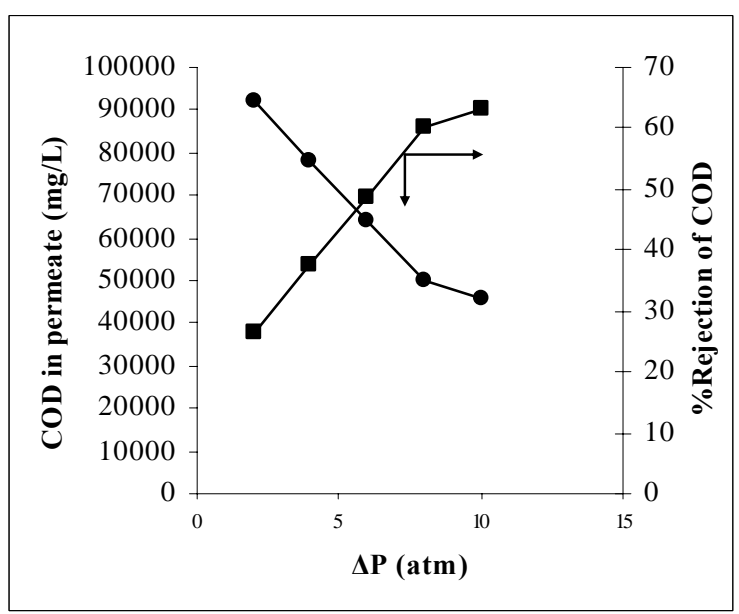

Figure 3. Removal of COD as a function of pressure with UF process

Table 2. Effect of pressure on UF permeate characteristics

\begin{tabular}{|c|c|c|c|c|c|c|c|}
\hline $\begin{array}{c}\text { Pressure } \\
\text { (atm) }\end{array}$ & $\begin{array}{c}\text { SS } \\
\left(\mathrm{mg} \mathrm{l}^{-1}\right)\end{array}$ & $\begin{array}{l}\text { COD } \\
\left(\mathrm{mg} \mathrm{l}^{-1}\right)\end{array}$ & $\begin{array}{l}\text { Colour } \\
\text { (Pt. Co. } \\
\text { Scale) }\end{array}$ & $\begin{array}{c}\text { Chlorides } \\
\qquad\left(\mathrm{mg} \mathrm{l}^{-1}\right)\end{array}$ & $\begin{array}{l}\text { Sulphate } \\
\left(\mathrm{mg} \mathrm{l}^{-1}\right)\end{array}$ & $\begin{array}{c}\text { BOD } \\
\left(\mathrm{mg} \mathrm{I}^{-1}\right)\end{array}$ & $\begin{array}{c}\mathrm{K}^{+} \\
\left(\mathrm{mg} \mathrm{l}^{-1}\right)\end{array}$ \\
\hline 2 & 10678 & 92000 & 724 & 52430 & 18792 & 27342 & 4165 \\
\hline 4 & 6700 & 78000 & 560 & 50895 & 12160 & 36829 & 3854 \\
\hline 6 & 3521 & 64000 & 501 & 48212 & 6840 & 26124 & 3420 \\
\hline 8 & 1780 & 50000 & 430 & 47585 & 3200 & 25161 & 3056 \\
\hline 10 & 1127 & 46000 & 398 & 45120 & 2164 & 24127 & 2674 \\
\hline
\end{tabular}

\subsection{RO experiments}

In the second stage, permeate obtained from the UF experiment was used as a feed for RO experiments. Several parameters have been studied with RO. A comparison of pure water flux, when distilled water and spent wash were used as feed, is shown in Figure 4, which clearly demonstrates the effect of osmotic pressure in RO transport. The flux for feed increased linearly from 12-20 atm. The comparison shows that the performance of the membrane was not affected by the fouling. In the pressure range of 12-20 atm, permeate was transparent. Effect of pressure on the removal efficiency of COD by RO is shown in Figure 5. It can be seen from Figure 5 that the $R_{0}$ of COD increased from 91.3 to $96.8 \%$. Effect of feed pressure on the removal efficiency of different ions through RO module is shown in Table 3.

It can be seen from Figures $6-9$ and Table 3 that the TDS permeate concentration was reduced from 33,561 to $68 \mathrm{mg} \mathrm{l}^{-1}\left(R_{0}=97.9 \%\right)$, BOD from 24,127 to $493 \mathrm{mg} \mathrm{l}^{-1}\left(R_{0}=97.9 \%\right)$, colour from 398 to $27 \mathrm{Pt}$-Co unit $\left(R_{o}=93.2 \%\right)$, chlorides from 45,120 to $76 \mathrm{mg} \mathrm{l}^{-1}\left(R_{o}=99.8 \%\right)$, sulphate from 2,164 to $6.4 \mathrm{mg} \mathrm{l}^{-1}\left(R_{o}=99.7 \%\right)$ and potassium from 2,674 to $143 \mathrm{mg} \mathrm{l}^{-1}\left(R_{o}=\right.$ 94.65\%).

Similar results were obtained by Nataraj et al. (2006), but with a hybrid NF and RO processes for the removal of colour and contaminants in the distillery spent wash and for a good water recovery rate. The reclaimed water by NF and RO processes could be reused for either domestic or industrial purposes. This hybrid process has proven its potential technological applicability for treating domestic and other wastewaters, by producing excellent effluent quality for safe and environmentally begins discharge, even under variable feed conditions (Couallier et al., 2006). 
Table 3. Effect of feed pressure on RO permeate characteristics

\begin{tabular}{|c|c|c|c|c|c|c|c|}
\hline $\begin{array}{c}\text { Pressure } \\
\text { (atm) }\end{array}$ & $\begin{array}{c}\text { SS } \\
\left(\mathrm{mg} \mathrm{l}^{-1}\right)\end{array}$ & $\begin{array}{l}\text { COD } \\
\left(\mathrm{mg} \mathrm{l}^{-1}\right)\end{array}$ & $\begin{array}{l}\text { Colour } \\
\text { (Pt. Co. } \\
\text { Scale) }\end{array}$ & $\begin{array}{l}\text { Chlorides } \\
\left(\mathrm{mg} \mathrm{l}^{-1}\right)\end{array}$ & $\begin{array}{l}\text { Sulphate } \\
\left(\mathrm{mg} \mathrm{l}^{-1}\right)\end{array}$ & $\begin{array}{c}\text { BOD } \\
\left(\mathrm{mg} \mathrm{l}^{-1}\right)\end{array}$ & $\begin{array}{c}\mathrm{K}^{+} \\
\left(\mathrm{mg} \mathrm{l}^{-1}\right)\end{array}$ \\
\hline 12 & 431 & 4000 & 42 & 297.9 & 25.6 & 1333.3 & 718 \\
\hline 16 & 240 & 2400 & 38 & 124 & 2.6 & 774.1 & 302 \\
\hline 20 & 94 & 1480 & 27 & 75.97 & 6.4 & 493.3 & 143 \\
\hline
\end{tabular}

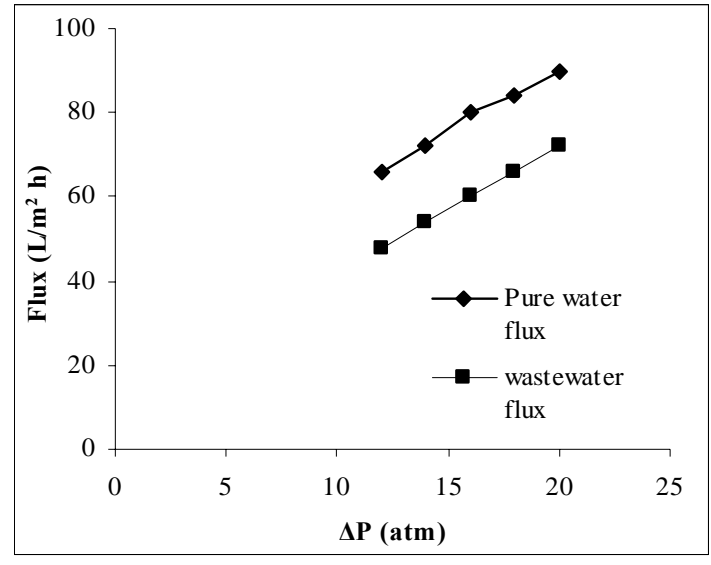

Figure 4. Comparison of flux, when distilled water and spent wash are used as feeds, as a function of pressure for $\mathrm{RO}$ process

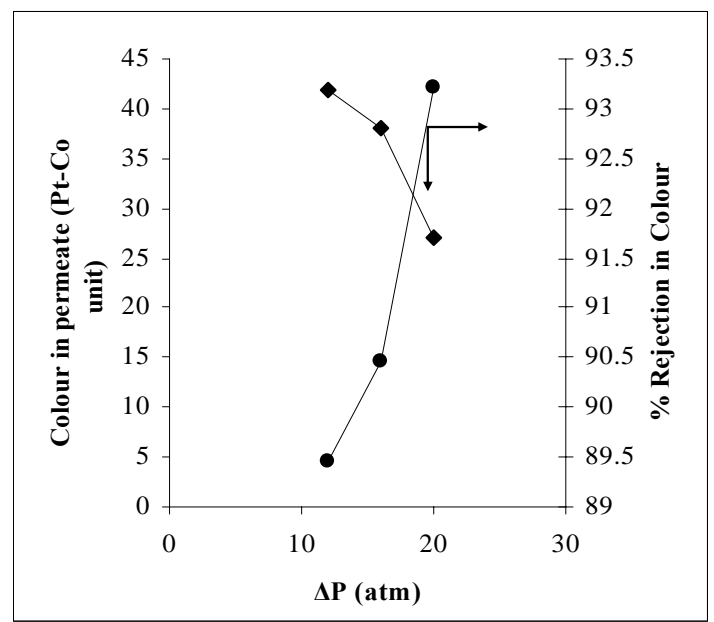

Figure 6. Removal of Colour as a function of pressure with RO process

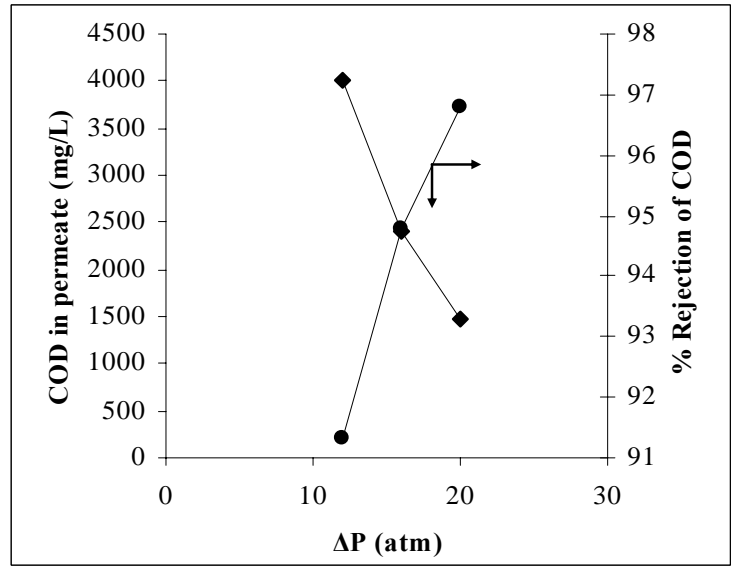

Figure 5. Removal of COD as a function of pressure with RO process

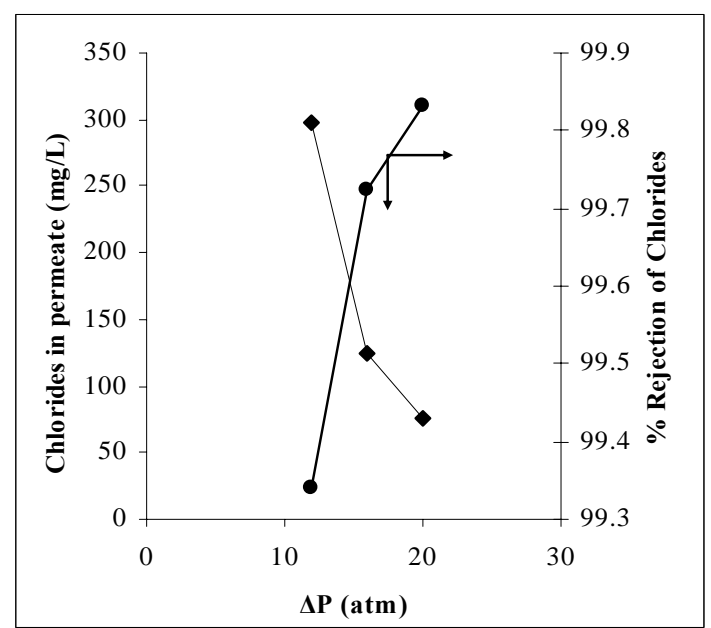

Figure 7. Removal of Chlorides as a function of pressure with $\mathrm{RO}$ process

\section{CONCLUSIONS}

The present membrane based separation study demonstrated that the UF and RO processes can be successfully used for the removal of colour and other contaminants from the distillery effluents. In the present case the best operating conditions for RO were observed to be 15 $\mathrm{L} / \mathrm{min}$ feed flowrate and $20 \mathrm{~atm}$ applied pressure, which gave the rejection efficiency of $97.9 \%$ and $96.8 \%$ for TDS and COD, respectively. The absence of heat application and a high rejection efficiency by $\mathrm{RO}$ shows that clean water can be produced economically instead of being vaporized by the energy intensive evaporation process. Recycling purified water could also enable to spare a major part of the ground water used in the distilleries at the fermentation stage. The main interest of recycling water is to be related with the management of the effluents by reducing fresh water consumption and wastewater treatment costs, small 
disposal volumes which will minimize the waste disposal costs and reduction in regulatory pressure.

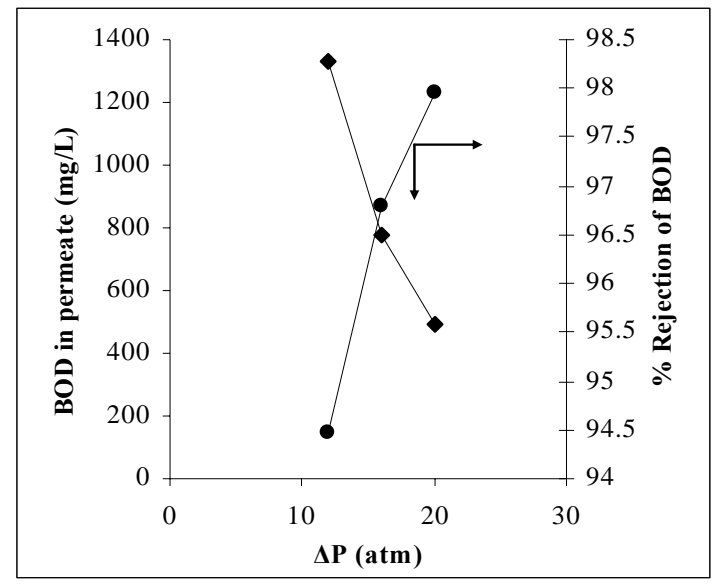

Figure 8. BOD removal as a function of pressure for RO process

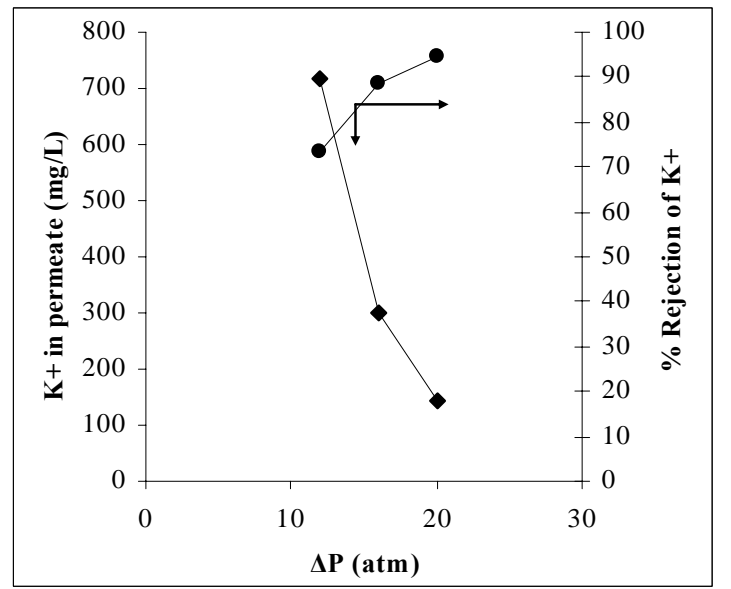

Figure 9. Potassium removal as a function of pressure for RO process

\section{ACKNOWLEDGEMENTS}

The first author (ZVPM) acknowledges the financial support from the Ministry of Human Resources Development, Government of India, New Delhi, under the TAPTEC Research Grant (No.F.27-1/2002. TS.V).

\section{REFERENCES}

Belkacemi K., Larachi F., Hamoudi S. and Sayari A., (2000). Catalytic wet oxidation of highstrength alcohol-distillery liquors, Applied Catalysis A: General, 199,199-209.

Clesceri L.S., Greenberg A.E. and Eaton A.D., (1998). Standard Methods for the Examination of Water and Wastewater, $20^{\text {th }}$ ed. American Public Health Association, American Water Work Association, and Water Environment Federation, Washington, DC.

Couallier E.M., Ruiz B.S., Lameloise M.L. and Decloux M., (2006). Usefulness of reverse osmosis in the treatment of condensates arising from the concentration of distillery vinasses, Desalination, 196, 306-317.

CPCB (2003). Central Pollution Control Board, Annual Report. New Delhi, India.

Dahiya J., Singh D. and Nigam P., (2001). Decolourisation of synthetic and spentwash melanoidins using the white-rot fungus Phanerochaete chrysosporium JAG-40, Bioresource Technology, 78, 95-98.

Mane J.D., Modi S., Nagawade S., Phadnis S.P. and Bhandari V.M., (2006). Treatment of spentwash using modified bagasse and colour removal studies, Bioresource Technology, 97, 1752-1755.

Murthy Z.V.P. and Gupta S.K., (1997). Estimation of mass transfer coefficient using a combined nonlinear membrane transport and film theory model, Desalination, 109, 39-49.

Nataraj S.K., Hosamani K.M. and Aminabhavi T.M., (2006). Distillery wastewater treatment by the membrane-based nanofiltration and reverse osmosis processes, Water Research, 40, 2349-2356.

Pant D. and Adholeya A., (2007). Biological approaches for treatment of distillery wastewater: A review, Bioresource Technology, 98, 2321-2334.

Ramana S., Biswas A.K. and Singh A.B., (2002). Effect of distillery effluents on some physiological aspects in maize, Bioresource Technology, 84, 295-297.

Saha N.K., Balakrishnan M. and Batra V.S., (2005). Improving industrial water use: case study for an Indian distillery, Resource, Conservation \& Recycling, 43, 163-174.

Sangave P.C. and Pandit A.B. (2006). Enhancement in biodegradability of distillery wastewater using enzymatic pretreatment, Journal of Environmental Management, 78, 77-85.

Zhang S., Yang F., Liu Y., Zhang X., Yamada Y. and Furukawa K., (2006). Performance of a metallic membrane bioreactor treating simulated distillery wastewater at temperatures of 30 to $45^{\circ} \mathrm{C}$, Desalination, $194,146-155$. 